\title{
Maria Ondina Braga: autobiografia, life-writing e relação
}

\author{
Isabel Cristina Mateus \\ Universidade do Minho - CEHUM
}

\begin{abstract}
Resumo: Viagem, vida e escrita confundem-se em Maria Ondina Braga, escritora portuguesa que andou pelos quatro cantos do mundo quer como turista, quer como viajante quer como emigrante. Eu vim para ver a terra é o título de estreia da escritora que em mais de uma entrevista afirmará "escrev[er] porque esse mundo que eu vivi revolucionou-me de tal modo a alma que eu tinha de o contar". Com este artigo pretende-se dar conta do encontro da escritora com a estranheza do mundo, com as diferentes paisagens e culturas e a diversidade de gentes que o habitam, mas também do encontro da escritora com a sua própria paisagem íntima, em permanente transformação durante a viagem. Do relato autobiográfico ao mais recente conceito de "life-writing", a viagem enquanto experiência íntima do mundo e encontro com a alteridade é condição desta escrita.
\end{abstract}

Palavras-chave: Maria Ondina Braga, literatura de viagens, mulheres viajantes escritoras, life-writing, autobiografia

\begin{abstract}
Travel, life and writing mix themselves when one speaks about Maria Ondina Braga, a Portuguese writer who has travelled the four continents as a tourist, traveler and emigrant. In several interviews, Maria Ondina Braga has declared "I write because this world that I lived in has revolutionized my soul so much that I had to tell it" and the title of her first book is, unsurprisingly, I came to see the land. This article aims to explore the writer's encounter with the strangeness of the world, with the different landscapes and cultures and the diversity of people who inhabit it, but also the writer's encounter with her own intimate landscape, in permanent change with travelling. From autobiography to life-writing, travel as an intimate experience of the world and encounter with identity and otherness are the condition of this writing.
\end{abstract}

Keywords: Maria Ondina Braga, travel literature, women travel writers, life-writing, autobiography 
"Mas um dia ainda hei de ir, sem me importar para onde o ir me levará” Clarice Lispector, Aprendendo a Viver-Imagens

\section{Cartografia(s): a viagem como predestinação}

Poucas escritoras (e escritores) da literatura portuguesa terão um percurso de vida que melhor se confunde com a ideia de viagem ou uma história tão intensamente multicultural como Maria Ondina Braga. Poucas escritoras (e escritores) terão uma cartografia pessoal e literária tão vasta como a sua, desde logo em extensão geográfica. Dizer isto é já dizer muito da singularidade da mulher e escritora, daquilo que faz da sua voz uma voz única como aqui procurarei mostrar.

Mulher de perfil discreto e solitário, aparentemente frágil, Maria Ondina Braga fez-se muito cedo aos caminhos do mundo afirmando-se como uma voz absolutamente inconfundível na literatura portuguesa do século XX, num século que, pela emergência de uma escrita no feminino, se afirmou como o "século das mulheres".' Inconfundível, antes de mais, porque em nenhuma outra voz feminina a experiência da viagem, a vivência desterritorializada e o olhar multicultural se conjugam de forma tão íntima e dialogante. Inconfundível também pelo timbre único que essa experiência e esse olhar conferem à sua escrita e, muito particularmente, pela intensidade ou pela coloração distinta que lhe imprime a experiência do Oriente (e em especial de Macau) ${ }^{2}$ que, longe de constituir uma marca de exotismo literário, antes se configura como um elemento aglutinador de espaços e de tempos, entrelaçando vivências, viagens e lugares, incorporando imagens e memórias.

Valerá talvez a pena evocar aqui brevemente esse percurso, antes de avançar. Maria Ondina Braga nasceu na cidade nortenha ${ }^{3}$ do seu apelido, uma cidade pequena, então acentuadamente provinciana e conservadora, feita de "pedras do tempo dos romanos e Nossas Senhoras de todos os nomes” (Braga 1976: 6), uma cidade crescendo à sombra tutelar da Sé. Mas cedo a escritora sentiu em si o apelo da viagem e da itinerância como condição de vida, a ânsia de desconhecido ou, na expressão de Paul Theroux, de estar "alhures” (2012: 7): "partir é bom, mas pensar em partir, melhor ainda. Quanto a mim, acho que tenho sempre chegado. Partir é esperança. Chegar, desencanto" (1976:79), dirá Maria Ondina, sem deixar de se auto-interrogar sobre essa condição: “donde vim eu que nenhum lugar me deixa saudades?" (1976: 82). Entre partidas e chegadas, a vida da escritora desenha um mapa que atravessa os quatro continentes, cruza mares e oceanos, viaja pelas várias estradas do mundo.

A pequenez da cidade natal, o enclausuramento do país durante o Estado Novo, o desejo de autonomia e de fuga a um passado marcado pela perda, o destino de solidão, levam Maria Ondina a sair para o Reino Unido, em 56, para estudar a língua inglesa; um investimento no futuro que lhe assegurou autonomia para viajar e trabalhar em diversos continentes como professora das línguas portuguesa e inglesa e, mais tarde, 
como tradutora. Em Londres e Worcester, estuda e trabalha como au pair, em casa da família Chalmers, acompanhando-a igualmente nas longas estadias de férias em Inverness, no norte da Escócia. Dali vai um ano para Paris, procurando aperfeiçoar os seus conhecimentos da língua francesa. Em 1960, está em Luanda e no ano seguinte parte para Goa onde trabalha na missão de Caranzalém (Pangim). Abandona a Índia no final desse mesmo ano, rumo a Macau, devido à “invasão" do território sob domínio português pelo exército indiano (ou, na designação deste último, devido ao movimento de “Libertação de Goa”). Em Macau, Maria Ondina exerce funções docentes no Colégio de Santa Rosa de Lima, visitando com frequência Hong-Kong e outras regiões da China. Viaja ainda até à Índia e ao Egipto, assim como ao Corno de África (Somália francesa e Djibuti), uma das zonas mais instáveis do mundo. Regressa a Portugal em 1964, fixa residência em Lisboa e faz várias viagens: à Madeira, aos Açores e Cabo Verde, mas também à Itália (Roma e Veneza), merecendo particular destaque a longa viagem ao Brasil no cruzeiro Infante Dom Henrique, em 1972, da qual nos deixará um diário de bordo inédito além de correspondência particular que em breve merecerão atenção noutro lugar. Em 82, voltará ao Oriente como professora convidada do Instituto de Línguas Estrangeiras de Pequim regressando, no final desse ano, definitivamente à capital portuguesa.

O percurso de Maria Ondina Braga é, a vários títulos, extraordinário para a época (e, porventura ainda, para os tempos actuais), tendo em conta a pluralidade de geografias e de lugares percorridos mas também a independência da mulher viajante solitária num tempo em que não havia viagens low-cost nem a mobilidade de hoje; tendo em conta igualmente a coragem da mulher nascida num país sob um regime ditatorial, conservador e fechado ao mundo, onde a discriminação de género impunha às mulheres o recato da casa como condição e destino. A coragem da escritora avulta, assim, num país que dissuadia a ousadia de mulheres viajantes de diferentes latitudes como Karen Blixen, Annemarie Schwarzenbach, Gertrude Bell ou Isabella Bird, em que era raro uma mulher viajar sozinha ou exigia às mulheres casadas autorização dos maridos para viajar. Não será demais sublinhar, por isso, a determinação da escritora, vencendo resistências e fragilidades várias, incluindo pessoais, como a doença que a condiciona (a epilepsia) e lhe aguça o desejo de autonomia. À semelhança destas mulheres viajantes, no passado e no presente, também Maria Ondina venceu a "maldição de Ulisses" (Serrano 2019:25)": a sua biografia não destoaria certamente deste volume de biografias dedicado a estas e outras viajantes no feminino. ${ }^{5}$

A invulgaridade do percurso da mulher e escritora manifesta-se ainda no modo particular como nele se conjugam e dialogam diferentes olhares e distintas experiências: o olhar da turista de passagem por certos locais, o olhar da viajante solitária demorando-se sobre a paisagem e as gentes, o olhar atento e simultaneamente estranho da emigrante confrontada com a experiência da alteridade ou mesmo, em 
certa medida, o olhar desterritorializado, estrangeiro, de quem vive a experiência do (auto)exílio. A singularidade do trajecto, bem como o perfil cosmopolita e multicultural da escritora cuja escrita estabelece pontes entre continentes, entre o mundo ocidental e o oriente, justificariam hoje, só por si, um olhar ainda mais atento sobre Maria Ondina.

Uma primeira nota que gostaria de sublinhar é a de que a viagem não é para Maria Ondina um tema ou figura retórica, uma convencional metáfora da vida, mas antes condição de vida e da própria escrita. Um destino ou predestinação para a errância e para a solidão que contém em si a marca de uma maldição ancestral: todo " $O$ viajante - avisa Michel Onfray- descende da raça de Caim” (Onfray 2009: 12). É, aliás, a própria escritora quem dá conta ao leitor deste destino que a acompanha desde que "veio ao mundo": vários biografemas presentes na narrativa autobiográfica Vidas Vencidas, enquanto signos fecundos que estabelecem pontes metafóricas entre a vida e a escrita, assim o indiciam. ${ }^{6}$

Desde logo, o comportamento estranho da rosa-de-jericó no dia do seu nascimento, numa sexta-feira treze. A planta seca, oriunda do deserto africano e evocando os mares do sul, tem a particularidade de renascer se colocada em água, um processo de transformação que a crença popular minhota usava como uma espécie de relógio para prever e medir a duração do parto: "Falar da rosa-de-jericó e da recusa da planta em florir na ocasião do meu nascimento seria nada mais nada menos que falar dos mitos e dos medos que então presidiam aos partos" (Braga 1998: 13). Ora estranhamente a rosa-de-jericó recusa-se a abrir no momento do nascimento de Ondina, num prenúncio de independência e de solidão da mulher que há-de converter-se numa imagem fundamental da mitografia ondiniana, reaparecendo em vários momentos da sua escrita: "Pois muito embora esteja provado que o período da independência se verifica no sexo feminino a partir dos onze anos, comigo penso até que foi prematuro. Talvez desde que vim ao mundo por obra e graça da rosa-de-jericó. [P]redestinação para viver sozinha?" (idem: 151).

O destino nómada manifesta-se igualmente na escolha do nome Ondina a partir de uma lista de nomes sugeridos por um irmão do pai, emigrado no Brasil, nome que deixa a mãe assustada por não fazer parte da onomástica dos santos do catolicismo: Ondina, sereia dos lagos e dos mares, ninfa das águas da imaginação e do desconhecido, transporta em si um destino de mobilidade que a escritora há-de cumprir ao longo da vida. Nomadismo, vida em trânsito, premonitoriamente inscritos no mapa do tecto na sala da casa de família, na Avenida Central, em Braga, com os quatro continentes representados por figuras femininas esculpidas a gesso em cada canto: "Europa, Ásia, África, América. Tão velha a casa que, ao ser construída, decerto não se conhecia ainda a Oceânia”, comenta a voz narrativa de Vidas Vencidas (Braga 1998: 86). Talvez por não constar do mapa do tecto (ou do destino), Maria Ondina não terá ido à Oceania, mas nem por isso a sua cartografia literária deixou de ter a extensão do mundo. 
Para a escritora, o apelo da viagem é ainda um destino familiar, vocação migrante ou itinerário genético que tem como lugares marcantes o tio do Brasil que lhe deu o nome, o tio Luís, fabricante de móveis em Braga (regressado de Paris, onde aprendera com os mestres da Art Déco) e encarregado da educação da escritora depois da morte do pai. Mas também a mãe, viajante em sonhos pelas terras distantes da irmã Glória, emigrante no Brasil: duas figuras tutelares com quem Maria Ondina aprenderá a arte de contar histórias, arte originalmente indissociável da experiência da viagem, como testemunham narrativas fundadoras como a Odisseia ou as Viagens de Marco Pólo. A narrativa de viagem é, lembra o viajante Paul Theroux, "a mais antiga do mundo, a história que o errante conta ao povo reunido à volta da fogueira depois do seu regresso de uma jornada. "Isto foi o que eu vi" -notícias do mundo mais vas to; o bizarro, o estranho, o chocante, histórias de animais ou de outras pessoas. "São como nós!” ou “Não são nada como nós!”. A história do viajante tem sempre a natureza da reportagem" (Theroux 2012: 8).

A predestinação da viagem coincide em Maria Ondina com a predestinação da escrita, como sugere o título de estreia da autora na narrativa: " $E u$ vim para ver a ter$r a$. Em mais de uma entrevista, e por diversos modos, a escritora deixará clara esta ligação: "escrevo porque esse mundo que eu vivi revolucionou-me de tal modo a alma que eu tinha de o contar" (Braga 1968). A escrita é, deste modo, para Maria Ondina o relato do encontro da escritora com a estranheza do mundo, com as diferentes paisagens e gentes que o habitam, mas também do encontro com um território não menos desconhecido ou estranho, a sua própria paisagem íntima, mental, em permanente transformação durante a viagem.

\section{A viagem como experiência íntima do mundo: olhar caleidoscópico e sensa- cionismo}

Só quis ver como se não tivesse alma.

Só quis ver como se fosse apenas olhos.

Alberto Caeiro, Poemas Inconjuntos

Reflectindo sobre o incremento das narrativas de viagens a partir dos finais dos anos 70 do século XX, Susan Sontag viu na moderna literatura de viagens uma "literature of disappointment”: por seu turno, Claude Lévi-Strauss afirmava em entrevista, em 1999, com a autoridade do antropólogo que vira o mundo durante mais de noventa anos: “à face da terra já não há nada para descobrir. É uma tristeza” (Leme 2009). Mais recentemente, Robert Macfarlane interrogava-se na revista Granta sobre a possibilidade de a literatura de viagens estar morta nos dias de hoje, num tempo em que o turismo de massas, a democratização das viagens aéreas, a homogeneização global e a fotografia digital parecem ter tornado impossível a existência de qualquer "terra incognita" ou alteridade desconhecida e reduzido a viagem a um simples 
modo de reconhecimento. A resposta, segundo o escritor britânico, passaria antes pela mudança e pelo desafio: "The best writers rose to challenge by seeking not originality of destination, but originality of form” (2017).

Dir-se-ia que, desde meados dos anos 60, a escrita de Maria Ondina Braga antecipava já, e acompanharia nas décadas seguintes, a mudança de forma anunciada por Macfarlane, desde logo na relação que estabelece com o espaço. Não apenas pelo mapeamento íntimo invulgar a que a sua escrita procede, mas também pela cartografia viajante que desenha: os lugares viajam, mudam de geografia, coexistem no mapa da memória e da escrita, numa originalidade que não pode deixar de ser sublinhada. ${ }^{8}$ Assim como não pode deixar de ser igualmente destacada a importância do olhar e a "assimilação do protagonismo da visão ao registo sensitivo dos outros sentidos" que, como observou Isabel Cristina Rodrigues (2019: II2), constitui uma das marcas originais desse íntimo mapear da terra.

No duplo encontro da escritora com a alteridade do mundo e consigo própria, sobressai a marca de um olhar de uma "delicadeza quase física", ${ }^{9}$ um olhar que não se confina a descrever o que observa, foge do pitoresco e do postal turístico, ${ }^{10}$ procurando dar conta, nas palavras de Virginia Woolf, de "todos os traços da passagem de uma mente pelo mundo" (2018:127). Talvez devesse dizer mais rigorosamente, no caso particular de Maria Ondina, procurando dar conta de todos os traços "da passagem de um olhar" pelo mundo. De um olhar que veio "para ver a terra".

A escrita de Maria Ondina Braga distingue-se por esse olhar pousado sobre as coisas da terra, demorando-se em cada uma delas como se nada mais houvesse para ver, um olhar atento e, simultaneamente, "de ternura sobre as árvores, os bichos, os homens e as mulheres, sobretudo os mais simples, os mais discretos na paisagem do mundo" (Mateus 2018: 6I). Um olhar que, todavia, não deixa de convocar, justapor e confrontar diferentes paisagens e gentes, distintos tempos narrativos, lugares, imagens, sensações num caleidoscópio permanente de fragmentos e de sentidos.

O olhar da escritora é este caleidoscópio interior, um "olho de dentro" que permite ver para lá da moldura do visível, fazendo apelo à imaginação e às sensações porque "imaginar é continuar a ver depois do trabalho primacial do olhar”. Ou, por outras palavras, como sublinha Isabel Cristina Rodrigues, invocando a lição de Cesário e de Caeiro," "é imaginar o não visto por sobre a factualidade do visto, olhar, para lá do ver primeiro, o que nos é possível tocar com as mãos e poder dizer depois, singelamente, eu vi, eu estive lá” (Rodrigues 2019: 113 ; 117).

Tal como para o poeta do olhar que deu pelo nome de Alberto Caeiro, também para Maria Ondina “a visão é uma sinédoque dos cinco sentidos, na medida em que contribui com a maior parte das informações que constituem a nossa percepção do mundo. Existe, por isso, - afirma Cabral Martins - um privilégio concedido à visão, e o ver torna-se o símbolo do Sensacionismo". À semelhança de Caeiro, também para Maria Ondina a "substituição dos pensamentos pelas sensações é uma operação de 
abertura ao real, ao mundo exterior”. ${ }^{2} \mathrm{O}$ olhar caleidoscópico de Maria Ondina é, antes de mais, este modo cambiante, sinestésico, íntimo, de ver e sentir o mundo. De pastorear o real.

Emoção paradoxal, fuga e desejo de desconhecido ao mesmo tempo, a escritora americana Carson McCullers ${ }^{13}$ definiu o apelo da viagem como uma espécie de homesickness, ${ }^{14}$ um sentimento indefinível no limiar "entre a nostalgia do familiar e uma ânsia do estrangeiro e do estranho". Para Maria Ondina, a viagem como a escrita (ou a escrita como a viagem) é, “acima de tudo”, nas suas próprias palavras, um meio de encontro consigo mesma, e a deslocação, como observa Paula Morão, a forma de a personagem se contar a si mesma ao "narrar o mundo" (1995: 745). Viajar é para a escritora não apenas ver, mas "palmilhar” a terra, uma visão táctil, um modo de sentir sob a pele a pele das ruas, das cidades e dos caminhos do mundo:

Palmilhei capitais europeias. Sonhei nas terras úberes de África os mais puros, os mais ardentes sonhos telúricos. Nasci numa cidade pequena com pedras do tempo dos romanos e Nossas Senhoras de todos os nomes. E não posso esquecer Paris - a sedução, o charme de Paris, seja na grandeza dos Campos Elísios, seja nas ruelas cosmopolitas e boémias de Saint Michel - de Paris. Tenho de lembrar o perfil dos monumentos de Londres por entre os véus do nevoeiro ou o chuvisco gelado. Necessito naturalmente de confrontar Angola com Macau para saber que há vida e saber que há morte. Mas, acima de tudo, quero encontrar-me comigo. Acima de tudo, desejo recordar a minha terra, as pessoas e os lugares que amei, outros passos...

Ou me volto para trás (fique embora transformada em estátua de sal) ou me perco neste mundo remoto, como que eterno, de uma raça sem idade.

Macau é, portanto, inédito para mim na medida em que eu própria nele me busco. 0 cenário que contemplo das janelas sobranceiras da sala onde ensino tem em Março o cinzento-esfumado do Outono em Inglaterra. Ao anoitecer de um dia morno, quando as criadas chinesas se aninham no pátio a tagarelar, o aroma das plantas tropicais traz-me à memória paisagens angolanas. E na distância dos olhos do povo é, umas vezes, a infância, outras vezes, a morte que vêm ter comigo. (Braga 1976: 6-7)

Acentuadamente autobiográfica (ou autoficcional), a escrita constitui o relato dessa experiência íntima, sensorial, do mundo que é para a escritora a viagem: "escrevo porque a experiência que colhi do mundo transborda-me para a pele”, afirmará a escritora em entrevista concedida à televisão (Braga 1968). Experiência onde as sensações (as cores, os sons, as texturas, os sabores e, muito especialmente, os cheiros do mundo) desempenham um papel fundamental, bem como a memória que o presente da viagem (ou o presente da escrita) proustianamente acorda.

Todavia, importa sublinhar que esta busca identitária, razão última da viagem, não é possível sem o confronto com a diferença e a relação com o outro que a viagem 
propicia. 0 encontro consigo mesma não se faz em oposição ao mas em coexistência com o mundo, com a simultaneidade de tempos e a pluralidade de espaços, de geografias e de lugares pelos quais a escrita viaja, fazendo con-viver culturas e vozes diversas. Assim, o céu de Macau, em Março, tem a cor "cinzento-esfumado do Outono em Inglaterra”; o aroma das plantas tropicais traz à memória da voz narrativa as "paisagens angolanas”; as avenidas e ruelas de Paris (Campos Elísios e Saint Michel), os monumentos de Londres, confundem-se "por entre os véus de nevoeiro ou o chuvisco gelado”; as "terras úberes de África” convivem com as “pedras” antigas da cidade natal. Por seu turno, num outro registo de Estátua de Sal, as pedras de Braga coexistem no caleisdocópio do olhar com as pedras vindas de outros lugares, procurando a voz narrativa não apenas buscar-se na pluralidade de espaços, mas também ver, registar a alma de cada lugar, as histórias por contar, escutar e escutar-se (n)os silêncios e (n)as vozes, humanas, de animais, (n)a voz do vento e do deserto:

Variáveis, em cada terra, as pedras. Amarelas, pretas, húmidas, aqui em Macau. Brancas em Braga; e no Verão, lembram ossadas-uma cidade de ossos, um claro, vasto, saudável cemitério.

Nas Quedas do Duque de Bragança, em Angola, impressionaram-me as achatadas, ruivas, por onde a água enlouquecida a despenhar-se no abismo -lájeas enormes, de xisto ferraginoso, onde nas noites quentes noivavam os crocodilos.

(...) Quem não sentiu já o sortilégio da pedra? Quem não sofreu desgosto por uma igreja, uma eira, um tanque de cimento armado? (...) Na Grande Mesquita do Cairo, as paredes eram de alabastro e o guia, um beduíno de manto e barbas, acendeu um fósforo para que os visitantes comprovassem a transparência rosada do fino mármore. Quanto orgulho no seu gesto! Dir-se-ia que estava a exibir a beleza autêntica de uma filha.

As Pirâmides pareceram-me a própria pedra em exaltação, como se mãos humanas lhe não houvessem tocado, como se fosse tudo obra do vento e do deserto (1976: 139-140).

De modo idêntico, na viagem de comboio de N'Dalatando a Malanje, em Angola, a paisagem africana convive com as paisagens do Minho, trazidas pela leitura de $A$ Brasileira de Prazins que faz rir a narradora e, com ela, toda a carruagem. Assim como a névoa onírica ou rememorativa que afecta o "olho de dentro" descobre nos véus das viúvas a caminho do cemitério, na Rua de S. Vicente, em Braga (que a adolescente vê a caminho do liceu), os véus das mulheres de Jibuti, com os quais se confundem e dialogam:

Ao liceu, chegava pois pela Rua de São Vicente. Visto ser também o sentido do cemitério, casas funerárias, enterros, homens e mulheres de preto, senão o fumo na manga ou na lapela. Que as viúvas, essas de crepes pela cara. Tal ainda hoje as mulheres de Mafoma seja qual for a sua situação. A Sura das Mulheres ordenando que elas se ocultem nos 
véus a fim de se absolverem dos pecados dos homens. Vi-as assim em Jibuti, na Somália Francesa. Véus cor de fogo. Os seus rostos como se incendiados. (1998: 62-63)

A viagem física é deste modo para Maria Ondina uma constante viagem interior: deslocação pela memória, itinerância pelos caminhos da imaginação e pelos livros que fazem parte da bagagem, física ou mental, um caleidoscópio de imagens. Confirmando o desejo manifestado pela escritora de "ver a terra” e dar conta de tudo o que nela há para ver, este olhar em movimento não se limita a um registo descritivo, antes traduz o inebriamento perante o real (um real excessivo, como no caso de Angola), fazendo transbordar para o plano da escrita toda a gama de sensações através das quais se constrói a percepção imaginativa. O sensacionismo que atravessa a escrita ondiniana é um modo de mapeamento íntimo do mundo, de ler lendo-se na tatuagem que as sensações imprimem na pele, (incluindo na pele da imaginação). Como nos mostra, por exemplo, a crónica sobre os mercados do mundo que a escritora "palmilhou”, trazidos ao olhar pela imagem do mercado de São Paulo, em Luanda (igualmente presente numa crónica de Passagem do Cabo) e pela exuberância vital da terra angolana:

Azuis os panos, as escamas dos peixes e a pele dos indígenas. Manhãzinha e o sol já ardia. Ah, se não fossem as palmas das palmeiras e o caniço dos toldos! Azuis as contas dos colares, as conchas e as cobras. Azul o sono do menino mulato às costas da mãe negra que vendia bolinhos de jinguba. (...). Mercado de São Paulo, em Luanda. Jindungo, dendém, corpos suados, e a terra ressequida à espera da monção.

Nos mercados de Goa dominava o vermelho. Colorau, canela, sementes picantes, pedras ruivas de azar, o brinco de oiro na narina, as bocas cor de fogo de mascar a folha de bétele. Então as gemas cozidas ao sol nos mercados chineses, os ovos pretos, apodrecidos debaixo do chão, que se ofereciam nos dias de festa, a banana roxa, com sabor a húmus, o lai-chi de aroma suave, as línguas chamejantes das mangas. (...) 0 mercado-barco no porto interior, a chocalhar panelas e loiça, passava por entre as sampanas, os juncos e as lorchas com fumos gordurosos de comida - o fartum do peixe seco e das couves salgadas a embrulhar o muito antigo de lodo, de limos e de linfa.

Nos mercados brasileiros, baianas de saia rodada e colares de feitiço, vendiam vatapá, cuscuz, bolo de milho. (...) Ervas de magia. Amuletos. Imagens de santos em madeira de jacarandá.

No mercado de camelos em Jibuti era o enigma dos rostos das mulheres por trás dos véus cor de cravo e o cheiro cálido do leite e da lã.

Passando o famoso mercado de Portobello Market das antiguidades e dos turistas americanos, lembro os pequenos mercados ingleses das market towns, com lavradeiras velhas de gabardina e chapelinho de veludo e o seu home-made bread, a sua home-made butter. (...) Uma cena de há talvez quinze anos que podia ter pertencido ao tempo da Rainha Vitória, a uma página de Charles Dickens. 
Da minha infância, as feiras minhotas onde as melancias se calavam com navalhas de ponta e mola, as vendedeiras de limonadas e de tremoços, alguidares de barro, ciganos, o jogo da vermelhinha.

E quando em Paris se me deparou um mercado de pássaros no recanto da vasta praça? 0 pipilar das aves a fazer esquecer o ruído do trânsito. Nas penas, as tintas de todos os quadros impressionistas. Penoso o farfalhar de asas contra as grades das gaiolas. 0 vendedor em cadeira de rodas: tinha perdido as pernas num golpe de metralha na Segunda Guerra Mundial.

O intenso visualismo da crónica, a vitalidade da cor, mudando de mercado para mercado (o azul dos panos das mulheres angolanas, das escamas de peixe e da pele dos indígenas; o vermelho e os ocres das especiarias de Goa, "as bocas cor de fogo de mascar a folha de bétele”; o preto dos ovos chineses e o roxo das bananas; os véus cor de cravo das mulheres de Jibuti, toda a paleta de cores impressionistas nos pássaros do mercado de Paris) dão conta não apenas da diversidade e do frémito de vida que caracteriza estes mercados, mas também do deslumbramento do olhar; um olhar que convoca outras sensações, todo um mundo de formas tangíveis, de sons ("farfalhar de asas", "chocalhar de panelas" ou de colares), de vozes, de sabores (jindungo, "bolinhos de jinguba", sementes picantes, bananas roxas, melancias, limonadas") e de cheiros ("corpos suados, colorau, canela, fartum do peixe seco, aroma suave de lai-chi, fumos gordurosos, o cheiro cálido do leite e da lã”) que a imaginação acorda no presente da escrita, e através dos quais a voz narrativa procura encontrar-se consigo mesma na totalidade do mundo visto, muito para lá da limitada moldura topográfica de um qualquer visível. Busca que implica igualmente o estar atento às vozes e às histórias ocultas das gentes, histórias de vida onde cabem os sonhos da mãe negra do menino de sono azul, a magia das baianas de saia rodada, o mistério das mulheres somali de véus cor de cravo, as histórias dickensianas das vendedoras das market towns inglesas, os crimes e as paixões do Minho camiliano, as histórias de guerra do vendedor de pássaros do mercado de Paris, histórias tecidas de silêncio e desejo de liberdade ${ }^{15}$ que só o olhar atento, o "olho de dentro" da escritora pode entrever.

Mas todo este mundo é apenas pressentido, sugerido, entrevisto numa escrita que frequentemente recusa a sintaxe e adopta a elipse, a interrogação, a suspensão. Esta será, porventura, uma grande diferença relativamente a Alberto Caeiro, na medida em que a escritora se interroga sobre o sentido das coisas para lá do olhar sobre elas, ainda que esse sentido não passe pelo pensamento (que de algum modo a escrita de Ondina questiona) nem pela noção de verdade, mas antes pela pele, por uma compreensão intuitiva, emotiva, do mundo. Pelo mistério das coisas, como ela própria reconhece: "Vejo sempre um pouco para além da aparência. Há sempre um mundo de mistério para além da realidade. E os dois mundos como se confundem e se completam" (Braga 1968). 
O desejo de ir ao encontro de si que determina a viagem é, para Maria Ondina, indissociável desta intimidade com o mundo, do permanente "confronto", quero dizer, do encontro face a face, de diferentes tempos, diferentes geografias e culturas, distintas formas de alteridade, próximas ou longínquas: daí o registo etnográfico, antropológico que frequentemente encontramos na sua escrita. Em qualquer dos casos, uma forma de humana empatia, de abertura ao outro, de auscultar segredos e silêncios, escutar vozes outras e, em especial, as vozes das mulheres, silenciosas e quantas vezes silenciadas, a que a sua escrita dá voz. Sem preconceitos nem tabus, sem qualquer forma de discriminação, de domínio ou de supremacia. Esta a marca de água da sua escrita.

\section{Modos de viajar: autobiografia, life-writing e relação}

Há tempos, em conversa com um familiar da escritora, este confidenciava-me que uma das recordações que guarda de Ondina é a mala de viagem, os aeroportos, os comboios, a sensação de que ela estava sempre a “partir”. Reservo assim uma última nota para dizer que o meio de transporte utilizado pela escritora não é indiferente a este desejo de confronto com o outro que tenho vindo a sublinhar, além de, naturalmente, factor condicionante da experiência da viagem: a "viaggiatrice del mondo", como the chamou Daniela Graziani (2009:51), viaja de comboio, de avião, de barco, de carro e de autocarro, de táxi ou de metro, sem esquecer os sampans de Macau e o sam-lun-ché que sabemos ter usado. Todos os meios lhe servem para partir. Para se pôr em fuga. Muito embora na tipologia da viagem esboçada em Estátua de Sal, mereçam destaque apenas três meios de transporte, aqueles que envolvem as viagens intercontinentais ou de longo curso e, por isso, mais sedutores para a viajante:

Se um dia soubesse contar das minhas viagens e das pessoas que nelas conheci, penso que teria um assunto de romance.

Primeiro, as viagens por mar. Há na vida a bordo certa intimidade, ao mesmo tempo espontânea e fictícia, que marca tanto os viajantes como a tripulação de um sinal humano e fútil. É-se nessas viagens mais sério e mais insensato do que nunca. Creio mesmo que ali, no meio das águas, cada qual se mostra o que deveras é, com as suas grandezas e misérias, como se, postos de parte preconceitos e medos, todos quisessem, enfim, representar, o papel que lhes ditou o grande autor.

Tais viagens são, sem dúvida, as mais interessantes e as mais inverosímeis, também. 0 encanto que a ociosidade e o mar concedem àqueles dias no barco desfaz-se logo que se anuncia o porto de desembarque, ninguém se conhecendo mais depois, cada um ingenua e precipitadamente ocupado em reajustar a máscara do mundo.

A seguir, as viagens aéreas - um flirt no aeroporto de escala, palavras de amor a voarem a 900 à hora-, viagens onde, na ironia do tempo e da distância, perpassam sentimentos de asas. 
E por fim as de comboio, que essas, permitindo maior comunicação com a Natureza, são as que despertam simpatias fraternais. (Braga 1976: 167-168)

Se as viagens aéreas são demasiado velozes, demasiado voláteis para permitir o encontro humano em "comunicação com a Natureza”, já as viagens de comboio permitem um espaço de confidência e intimidade, favorável ao despertar de "simpatias fraternais" e à cumplicidade das histórias. A tipologia da viagem servirá a Maria Ondina para justificar a sua preferência pelos comboios e servir de prelúdio ao encontro com Ângela, a viajante desconhecida que revela ter fortes traços de afinidade com a escritora, gerando nela uma profunda empatia:

Chamava-se Ângela, ensinava inglês num jardim-escola em Lisboa, e ia a Inglaterra por um mês para praticar a língua. (...) Ângela havia sofrido. Eu havia sofrido. Ela sabia tudo. A mim nada me espantava. Tínhamos comido à mesma mesa a "omelette au jambon" e o pão branco da nossa primeira refeição em França. Éramos companheiras de viagem, a grande viagem da vida. $(1976: 168 ; 172)$

Entre as várias histórias de vida das gentes anónimas com quem se cruzou nos caminhos do mundo, Maria Ondina mostra-se particularmente atenta às mulheres e à condição feminina, aos silêncios, conflitos e interditos sociais que as envolvem, em especial os relacionados com a sexualidade e a maternidade. A história de Ângela, como as histórias de vida de muitas outras mulheres, de diferentes geografias, de diferentes etnias e culturas, atraem o olhar da escritora numa cumplicidade sem fronteiras nem barreiras ou véus de qualquer etiologia.

Encontrar-se consigo e com o outro, enfrentar o desconhecido, desocultar o invisível e o indizível, desafiando estereótipos, crenças, tabus, questionando verdades, são afinal as razões de viajar de Maria Ondina, a matéria de que é feita a sua vida. Uma e outra, viagem e vida, profundamente interligadas numa escrita que se move numa pluralidade de géneros, da autobiografia à ficção ou, de um modo mais aberto ainda, ao moderno conceito de "life-writing" $i^{16}$ interligação desde logo potenciada pelo próprio hibridismo da escrita viática, caracterizada pela porosidade de fronteiras e de géneros e pela permanente oscilação entre o facto e o ficto.

Não há na escrita de Ondina um convencional relato de viagem, antes fragmentos, registos diarísticos, biografias e autobiografias ficcionais, crónicas, cartas, memórias, ficção (contos e romances), imagens que caleidoscopicamente se transformam, confrontam e reconfiguram de obra para obra, obrigando o leitor, também ele, a uma leitura nómada, errante. A esta construção "de linhas de fuga e de imagens que se expandem em todas as direcções”, rizomaticamente, chamou Edouard Glissant “poética da Relação", na medida em que "toda a identidade se prolonga numa relação com o Outro" (200I: 2I). Ou, nas palavras de Maria Araújo Silva, “num “entre-dois” em 
permanente construção e alvo de fascínio e estranhamento"."7

Para terminar, "Eu vim para ver a terra" é mais do que o título original do livro de estreia narrativa de Maria Ondina Braga, em 1965 (revisto e publicado em 94 com o título de Passagem do (abo): é a sua declaração de princípio como escritora, proclamada então no deslumbramento genesíaco da paisagem africana:

Eu vim para ver a terra. Eu toda livre de compromissos, quer apostólicos quer políticos, e assim de qualquer miragem materialista, qualquer fim, qualquer fixação - alguém porventura melhor do que eu para afirmar por escrito, e com letras maiúsculas, como vale a pena vir à África para ver a terra? (...) Paisagem, em suma, que inesperadamente recupero ao pisar do solo de África. Como se tornasse ao princípio de mim. Ao princípio do mundo? (1994: 17)

Toda a viagem é um "ensaio no desconhecido" (Theroux 2012: 10). Um princípio de mundo. Como aquelas imagens que desfilam no atlas da memória do poema de Jorge Luis Borges, A Felicidade, onde "tudo acontece pela primeira vez, mas de maneira eterna" (Borges 20ı0: III, 322). Maria Ondina vê o mundo como se fosse a primeira vez, mas de maneira eterna. Procurando olhar cada recanto da terra como se fosse "apenas olhos" atentos à "espantosa realidade das coisas"(Caeiro 200I: 104). E à pluralidade das gentes. Olhos de dentro despidos dos véus do pensamento, como Caeiro. Olhos sinestésicos, caleidoscópicos, onde o imaginar se tinge de compreensão e de afecto, mesmo se emotivamente contidos ou discretos.

"Visões largas, - escreveu um dia Mark Twain (2010) - sadias e benevolentes de homens e de coisas não se podem adquirir vegetando toda a vida num cantinho da Terra". Poucos viajantes, contudo, se aventuraram por tantas estradas do mundo ou souberam fazer dele a sua casa como Maria Ondina. Talvez por isso esta escrita, atenta às coisas, às cores, aos sabores, texturas e cheiros, às vozes e sons, nos dê a ver a amplitude da terra que desconhecemos ou simplesmente ignoramos e nos devolva à respiração do mundo.

Viajar com Maria Ondina Braga talvez seja um poderoso antídoto contra todas as formas de preconceito, de desigualdade ou de intolerância. Contra todas as formas de dogmatismo ou de individualismo. Uma lição de abertura ao outro do mundo e aos outros, nossos concidadãos no mundo, contra tudo aquilo que nos confina ao sedentarismo ou, oferecendo-nos a ilusão de viajar um ecrã global, nos condena a "vegetar toda a vida num cantinho da terra" (Mateus, 2019:89). Razão mais do que suficiente para partir e, como Maria Ondina, nos fazermos ao caminho nos dias de hoje. 


\section{Notas}

* Isabel Cristina Mateus é licenciada em Línguas e Literaturas Modernas pela Universidade de Coimbra e doutorada em Ciências da Literatura (Literatura Portuguesa) pela Universidade do Minho onde é Professora Auxiliar no Departamento de Estudos Portugueses do Instituto de Letras e Ciências Humanas. É investigadora do CEHUM (Centro de Estudos Humanísticos) e coordenadora responsável pelo grupo de investigação Poéticas em Língua Portuguesa. É co-editora de vários volumes temáticos e autora de diversos estudos sobre autores da literatura portuguesa moderna e contemporânea publicados em livros e revistas da especialidade, nacionais e internacionais, entre os quais “Kodakização” e Despolarização do Real: para uma Poética do Grotesco na Obra de Fialho de Almeida (Caminho, 2008) recebeu o Prémio de Ensaio Óscar Lopes (2007) e Prémio de Ensaio Pen Clube (2008). Co-coordena actualmente a edição da Obra Completa de Maria Ondina Braga pela INCM.É membro da direção da Associação Portuguesa de Escritores e membro da Comissão LATE do Instituto Camões.

'O “século das mulheres" diz respeito não apenas à mudança trazida pela publicação, em 1972, nas vésperas da Revolução, das Novas Cartas Portuguesas de Maria Isabel Barreno, Maria Velho da Costa e Maria Teresa Horta e às vozes femininas que, na poesia ou na ficção, a partir daí se afirmaram no espaço literário, mas também a todo um conjunto de vozes femininas que foram abrindo caminho a essa mudança: entre outras, Irene Lisboa, Florbela Espanca, Agustina Bessa-Luís, Maria Velho da Costa, Natália Correia, Natália Nunes, Maria Gabriela Llansol, Sophia Andresen, Fiama Pais Brandão, Fernanda Botelho, Maria Judite de Carvalho e, naturalmente, Maria Ondina Braga.

${ }^{2}$ Como sublinhou J. Carlos Seabra Pereira, é “em Macau, e em boa parte pela relação com Macau, que o destino de criadora literária se impõe irreversivelmente, com a ironia fecunda de passar por uma intérmina demanda de si mesma - também ela, como a sucessiva reconfiguração da sua escrita, indissociável da ligação a Macau.

Não se trata, pois, do fenómeno muito mais comum em que Macau, a sua geografia física e humana, as suas vicissitudes históricas e as peculiaridades sócio-culturais, se tornam matéria temático-formal de algumas obras de escritores portugueses (...). Na obra de Maria Ondina Braga há um continuum de vinculação genésica a Macau (“na pista da China” como diz algures), como espaço único (e cadinho único) de múltiplas linguagens e de identidades várias e abertas, nem totalmente chinês, nem totalmente português, nem completamente antigo nem moderno, mas flutuando algures em lugares intermédios (Pereira 2015: 258).

${ }^{3}$ Sobre os lugares nortenhos de Maria Ondina e, em especial, sobre a cidade de Braga, veja-se o roteiro literário Viajar com... Maria Ondina Braga (Mateus 2018).

${ }^{4}$ A exclusão da mulher da viagem até ao século XX constitui aquilo a que Sónia Serrano designa como "a maldição de Ulisses” (2019: 25), esse mítico herói que, contra todas as expectativas, conseguiu manter a sua mulher à espera durante vinte anos”. Segundo a autora, “[a]té bem adiantado o século XX, uma mulher que viajasse só era objecto de espanto, curiosidade ou escândalo, quando não o conjunto dos três sentimentos, traduzindo a estupefacção perante uma representante do "sexo" fraco a aventurar-se no domínio dos homens”. “A mulher e a viagem” (Serrano 2019: 27). 
${ }^{5}$ Sobre as biografias destas mulheres e a viagem no feminino, veja-se (Serrano 2019). Note-se que só na contemporaneidade surgirá neste volume o nome de uma viajante portuguesa, Alexandra Lucas Coelho.

${ }^{6}$ Cf. "A raiz e a árvore: identidade, memória e viagem em Maria Ondina Braga” (Martins/ Oliveira/ Mateus 2017: 108-114).

7 "The generalizing of travel results in a new genre of travel writing: the literature of disappointment, which from now on will rival the literature of idealization. Europeans visited America, prospecting the possibilities of a new, simpler life: cultivated Americans journeyed to Europe to appraise the Old World sources of civilizations - both often profess to be disappointed” (Sontag 1984).

${ }^{8}$ Como observam Shirley Foster e Sara Mills a propósito da escrita viática das mulheres oitocentistas, "Women travel writers have had to negotiate with the discursive framework of scientific writing, imperialism, aesthetics, and the ideology of the separate spheres in order to represent their travels spatially. (...) Much of the constitutive work for these frameworks had been undertaken by male travellers, geographers and artists. Women travel writers have thus had to try to position themselves somewhere in relation to these discourses of aesthetics, science and imperialism and find a voice for themselves amid these authoritative statements for surveying, analyzing, assessing and evaluating. Furthermore they have had to challenge the assumption that women within the public sphere are somehow "out of place". "Women and space" (Foster \& Mills 2002: 172). Num país onde é praticamente inexistente a tradição de mulheres viajantes do século XIX, o gesto “subversivo” de Maria Ondina Braga e a aparente simplicidade de uma escrita fora da moldura convencional dos géneros, são ainda mais significativos.

${ }^{9}$ Cf. "Maria Ondina”, testemunho de Hélia Correia (Mateus 20ı8: 7).

${ }^{10}$ Expressão auto-irónica, usada pela escritora numa carta escrita a bordo do navio cruzeiro Infante D. Henrique em viagem ao Brasil, entre 12 de Agosto e 19 de Setembro de 1972.

" "Tal como Maria Ondina Braga e Paulo Varela Gomes, Cesário e Caeiro vieram efetivamente para ver a terra, são dois observadores concentrados no labor minucioso da contemplação, dois pastores atentos do real ou, se quisermos, dois flâneurs de baudelairiana estirpe que preferem, como sublinha o próprio Baudelaire, “fixar residência no movimento” (Rodrigues 2019: ı09). Para Cândido Oliveira Martins, contudo, a narradora-viajante de Passagem do Cabo "está muito longe de se identificar com o flâneur moderno e contemporâneo. (...) Podendo partilhar uma certa solidão com este tipo humano e uma atracção pela errância (homo erraticus), a flânerie ondiniana apresenta-se profundamente implicada, quer em termos cognitivos, quer na perspectiva antropológica - ver para conhecer, o homem e o mundo. E nesse processo, observa agudamente, comenta sensivelmente, assimila intensamente” (2019: 65).

${ }^{12}$ Martins, Fernando Cabral, “A Noção das Coisas” (posfácio) (Caeiro 2009: 285; 282).

${ }^{13}$ Carson McCullers é, curiosamente, uma das autoras cuja biografia Maria Ondina Braga nos deixará no volume inédito Retratos com Sombra, volume que vem dar continuidade à série de biografias inaugurada com Mulheres Escritoras (1980) e da qual fazem parte nomes como Virginia Woolf, Jane Austen, Katherine Mansfield, Gabriela Mistral, George Sand ou Irene Lisboa, entre muitas outras.

${ }^{14}$ Em pleno contexto da Segunda Guerra Mundial, Carson McCullers define assim este sentimento: "It is a curious emotion, this certain homesickness I have in mind. With Americans, it is a national trait, as native to us as the roller-coaster or the juke-box. It is no simple longing for the home town or the 
country of our birth. The emotion is Janus-faced; we are torn between a nostalgia for the familiar and an urge for the foreign and the strange. As often as not, we are homesick most for the places we have never known”, “Look Homeward, Americans” (McCullers 1940: 74).

${ }^{15}$ Convém sublinhar que a crónica "Mercados" integra o volume A Revolta das Palavras, publicado em 1975, fortemente marcado pelos ventos da liberdade em Portugal. Daí que seja para a autora particularmente "penoso", impressivo, no mercado de Paris o "farfalhar de asas contra a grade das gaiolas" dos pássaros cujas "penas" anunciavam o colorido dos "quadros impressionistas".

${ }^{16} \mathrm{O}$ conceito de life-writing diz respeito a um vasto conjunto de narrativas, na primeira pessoa ou não, que vão desde a autobiografia, à biografia, diários, cartas, memórias, testemunhos, ensaios e, mais recentemente, formas digitais como os blogs. Estas histórias de vida ou relatos pessoais têm vindo a afirmar-se como um amplo campo de estudos na contemporaneidade, enquanto reflexo do individualismo extremo das sociedades modernas. De acordo com David McCooey, "the shift in the last two decades from auto/biography studies to life-writing studies was notably informed by feminist and postcolonial theory, as well as the rise of cultural studies, as seen in the critical attention given to auto/biographical subjects previously silenced, such as women, people of colour, Indigenous peoples, and (more recently) children. Such life-writing theory began from a critique of the human subject (simultaneously universalised and limited as male, European, self-present and autonomous), reconfiguring subjectivity as diverse, provisional and intersubjective. The life writing of such subjects was seen to deconstruct the supposedly secure limits of selfhood and auto/biographical expressions of selfhood" (McCooey \& Takolander 2017).

${ }^{17}$ Sobre esta "poética da Relação", veja-se o artigo “Segredo, identidade e Relação em Maria Ondina Braga” (Silva 2019).

\section{Bibliografia}

Braga, Maria Ondina (1998), Vidas Vencidas, Lisboa, Caminho.

-- (1980), Mulheres Escritoras, Lisboa, Bertrand.

-- (1976), Estátua de Sal (edição refundida e ampliada), Lisboa, Círculo de Leitores.

-- (1975), A Revolta das Palauras, Lisboa, Bertrand.

-- (1968), declarações de Maria Ondina Braga, RTP Arquivos (Noticiário Nacional de

Novembro), (II de Novembro). https://arquivos.rtp.pt/conteudos/declaracoes-demaria-ondina-braga/ (consultado em 19.16.2020).

Borges, Jorge Luis (2010), Obras Completas 1975-1985, Vol. III, Lisboa, Teorema.

Caeiro, Alberto/ Pessoa, F. (2009), Poesia de Alberto Caeiro (ed. de Fernando Cabral Martins e Richard Zenith), Lisboa, Assírio \& Alvim.

Foster, Shirley and Mills, Sara (eds) (2002), An Anthology of Women's Travel Writing, 
Manchester and New York, Manchester University Press.

Graziani, Michela (2009), Culture in Dialogo: Occidente e Oriente nella narrativa di Maria Ondina Braga, Firenze, Sassoscritto.

Leme, Carlos Câmara (2009), “À face da terra já não há nada para descobrir.É uma tristeza”, entrevista a Claude Lévi-Strauss, publicada em II de Abril de 1999. Ípsilon/ Público, 3 de Novembro 2009. https://www.publico.pt/2009/I1/03/culturaipsilon/noticia/a-face-da-terra-ja-nao-ha-nada-para-descobrir-e-uma-tristeza-140816। Macfarlane, Robert (2017), “Is travel writing dead?", in Granta 138, The Magazine of New Writing (Journeys), Winter, 9 Feb.

Mateus, Isabel Cristina / Martins, Cândido Oliveira (eds) (2019), Viagens e Culturas em Diálogo, Braga, Museu Nogueira da Silva/Universidade do Minho.

Mateus, Isabel Cristina (2019), "Paulo Moura e Maria Ondina Braga: viagens na minha terra e nas estradas do mundo", in Mateus, Isabel Cristina e Martins, Cândido Oliveira (eds), 2019, Viagens e Culturas em Diálogo, Braga, Museu Nogueira da Silva/Universidade do Minho.

-- (2018), Viajar com... Maria Ondina Braga, Guimarães, Opera Omnia/Direção Geral de Cultura do Norte.

-- (2017), "A raiz e a árvore: identidade, memória e viagem em Maria Ondina Braga”, in Martins, C. Oliveira / Mateus, Isabel Cristina (coord.) (2017), Maria Ondina Braga: (Re)leituras de uma Obra, Braga, Museu Nogueira da Silva/Universidade do Minho.

Martins, Cândido Oliveira (2019), "Para uma poética da viagem: Passagem do Cabo, de Maria Ondina Braga”, in Mateus, Isabel Cristina / Martins, Cândido Oliveira (eds) (2019), Maria Ondina Braga: Viagens e Culturas em Diálogo, Braga, Museu Nogueira da Silva.

Martins, Cândido de Oliveira / Mateus, Isabel Cristina (coord.) (2017), Maria Ondina Braga: (Re)leituras de uma Obra, Braga, Museu Nogueira da Silva/Universidade do Minho.

McCooey, David / Maria Takolander (eds) (2017), Life-Writing, Issue 3: "The Limits of Life-Writing”, vol. 14. https://www.tandfonline.com/doi/full/I0.1080/14484528.2 O17.1338910. (consultado em 02.07.2020)

McCullers, Carson (1940), “Look Homeward, Americans”, in Vogue, December, pp.74-75. Morão, Paula (1995), “Braga (Maria Ondina)”, in Biblos, Enciclopédia Verbo das Literaturas de Língua Portuguesa, vol. I, Lisboa, Verbo, pp.744-746.

Onfray, Michel (2009), Teoria da Viagem: Uma Poética da Geografia, trad. Sandra Silva, Lisboa, Quetzal.

Pereira, José Carlos (2015), “Vidas a deslado - A narrativa ficcional de Maria Ondina Braga”, in O Delta Literário de Macau, Macau, Instituto Politécnico de Macau.

Rodrigues, Isabel Cristina (2019), “Filhos de Cesário: o sensacionismo tranquilo de Maria Ondina Braga e Paulo Varela Gomes”, in Mateus, Isabel Cristina/ Martins, 
Cândido Oliveira (eds) (2019), Viagens e Culturas em Diálogo, Braga, Museu Nogueira da Silva/Universidade do Minho.

Serrano, Sónia (2019), Mulheres Viajantes, Lisboa, Tinta-da-China.

Silva, Maria Araújo (2019), "Segredo, identidade e Relação em Maria Ondina Braga”, in Mateus, Isabel Cristina e Martins, Cândido Oliveira (eds) (2019), Viagens e Culturas em Diálogo, Braga, Museu Nogueira da Silva/Universidade do Minho.

Sontag, Susan (1984), "Model destinations", in Times Literary Supplement, June 22.

Theroux, Paul (2012), A Arte da Viagem: Iluminações de Vidas nas Estradas, trad. de Freitas e Silva, Lisboa, Queztal.

Twain, Mark (2010), A Viagem dos Inocentes, Lisboa, Tinta da China. [1a ed. 1869].

Woolf, Virginia (2018), Viagens, selecção, tradução, introdução e notas de Jorge Vaz de Carvalho, Lisboa, Relógio d'Água. 